\title{
APROXIMACIÓN AL ENCUADRE DE LOS MEDIOS IMPRESOS EN TORNO A LA ATENCIÓN A VÍCTIMAS DEL CASO AYOTZINAPA, IGUALA-GUERRERO (MÉXICO)
}

Cruz García Lirios ${ }^{1}$ : Universidad Autónoma del Estado de México. México. garcialirios@yahoo.com

Francisco Rubén Sandoval Vázquez²: Universidad Autónoma del Estado de Morelos. México. sandovaz@hotmail.com

José Alfonso Aguilar Fuentes ${ }^{3}$ : Universidad Autónoma del Estado de México. México. jaaguilarf@uaemex.mx

\section{RESUMEN:}

La construcción de una agenda pública en materia de seguridad y pacificación supone el análisis de los medios de comunicación como emisores de temas concernientes a hechos de gran envergadura como el caso de los 43 estudiantes desaparecidos en Ayotzinapa. El presente trabajo se propuso analizar la difusión sistemática de los periódicos con respecto a la atención a víctimas y sus encuadres, considerando tres enfoques: conservadurismo, liberalismo y progresismo. Se llevó a cabo un estudio documental, exploratorio y retrospectivo con una selección no probabilística de 261 notas de prensa de circulación nacional. Se realizó un análisis de su contenido y se establecieron las frecuencias de difusión sistemática. Los resultados muestran que el periódico La Jornada realizó un encuadre cercano al enfoque progresista al difundir con mayor frecuencia la acción de grupos organizados de la sociedad civil respecto a la atención a víctimas en contraste con la acción

\footnotetext{
${ }^{1}$ Cruz García Lirios ${ }^{1}$ : Universidad Autónoma del Estado de México. México. garcialirios@yahoo.com

${ }^{2}$ Francisco Rubén Sandoval Vázquez²: Universidad Autónoma del Estado de Morelos. México. sandovaz@hotmail.com

${ }^{3}$ José Alfonso Aguilar Fuentes ${ }^{3}$ : Universidad Autónoma del Estado de México. México. jaaguilarf@uaemex.mx
} 
institucional o gubernamental. En referencia a la literatura revisada se advierte sobre la emergencia de esferas civiles en el proceso de gobernanza de la seguridad pública.

PALABRAS CLAVE: seguridad, agenda, violencia, víctimas, encuadre, verosimilitud, verificabilidad

\section{APPROACH TO THE FRAME OF THE PRINT MEDIA REGARDING THE ATTENTION TO VICTIMS OF CASE AYOTZINAPA, IGUALA- GUERRERO (MEXICO)}

\section{ABSTRACT:}

Building a public agenda on security and peace involves the analysis of the media as transmitters of issues concerning major events such as the case of 43 students missing in Ayotzinapa. The present study aimed to analyze the systematic dissemination of newspapers with regard to care for victims and their frames, considering three approaches: conservatism, liberalism and progressivism. A documentary, exploratory and retrospective study with a probabilistic selection of 261 notes national press was held. content analysis was performed and the frequencies of systematic dissemination settled. The results show that the newspaper La Jornada made a close approach to the progressive spread most often the action of organized groups of civil society regarding the care of victims as opposed to institutional or governmental action frame. Referring to the literature reviewed is drawn to the emergence of civil spheres in the governance process of public safety.

KEY WORDS: performance, security, violence, victims, framing, setting, priming

\section{INTRODUCCIÓN}

La ciencia que estudia el proceso de victimización lo considera como a) un efecto de la desviación supuesta de grupos delincuentes y su regulación punitiva a partir de las leyes de una cultura dominante; b) un síntoma del disenso pluralista e intercultural en donde las diferencias legitiman el establecimiento de marcos normativos, regulativos y punitivos y; 3 ) el reconocimiento de un conflicto en el cual subyace una sistema punitivo favorable a quienes tienen el poder económico, político o social

El énfasis en el ciclo de la víctima devela las diferencias entre los enfoques (Uvalle, 2011). De este modo, una aproximación conservadora asume a la víctima como un sujeto permanentemente en sufrimiento por el agravio que supone la violación a sus derechos y la espera de justicia (Fondevilla y Quintana, 2013). En este sentido, la 
minimización del delito es proporcional al impacto que genera la perpetración de la integridad (Gasca y Olvera, 2011). Los efectos en se manifiestan en diferentes niveles, pero es la víctima quien demanda al sistema punitivo el restablecimiento de sus derechos y la condonación de su integridad (Concimance, 2013).

En contraste, el enfoque liberal asume que el dolor causado a la víctima es secundario cuando de ajustar el agravió a los cánones de la cultura dominante como lo es la tolerancia y la justicia (Jiménez, 2009). Incluso, el agravió es asumido como un instrumento de reivindicación de un grupo oprimido por la cultura dominante, pero las diferencias entre perpetrador y víctima se pueden incrementar en la remisión y generar una mayor espiral de conflictos y violencia (Añanos, 2012).

Por último, el paradigma colectivista da por hecho que el perpetrador es un instrumento de quienes tienen el poder económico, político o social, ya que buscan imponer su cultura de dominación y para ello buscan en el delincuente una alternativa simbólica de estratificación, empero también asumen que la víctima sólo lo es mientras el evento ocurre, ya que ésta tiene la capacidad de revertir la agresión de diferentes formas e intensidades (Dorantes, 2012).

Por consiguiente, la atención a víctimas desde el conservadurismo consiste en la aplicación de la ley, desde el liberalismo más bien supone que cada caso no sólo es aislado, sino además está circunscrito a las diferencias entre los grupos (García et al., 2013). En virtud de que la igualdad ante la ley es lo más importante para el liberalismo, la víctima pasa a segundo término porque se privilegia su atención siempre y cuando demuestre la solides del sistema conciliador (Taguenca, 2012). Es cierto que las leyes favorecen a quienes tienen el poder o lo representan, pero desde la teoría colectivista es menester atender a la víctima asumiendo su posible conversión a perpetrador de la violencia por haber desarrolla una conformidad, opacidad y negligencia ante su caso y la de otras víctimas (Clemente et al., 2013).

La atención a víctimas está pensada como una fase preliminar a la paz pública, ya que son las instituciones encargadas de la seguridad quienes se encargan del cumplimiento de la ley, la impartición de justicia y el establecimiento de una agenda de seguridad (Tena, 2010).

Sin embargo, la reducción del sistema de seguridad al bienestar de los grupos e individuos obliga a discutir la rectoría del Estado como procurador de justicia, la atención a víctimas mediante el resarcimiento de sus derechos, la legitimidad de sus propuestas, la reivindicación de sus demandas o su participación en la construcción de una agenda pública (Jiménez, 2012).

El ciclo de atención a víctimas incluiría seis fases en torno a las que factores históricos y emergentes tales como la objetivación de la seguridad pública, el anclaje en percepción de inseguridad y la naturalización de los discursos e imágenes asociadas a la corrupción o impunidad generarían una sociedad civil que no sólo hereda las prácticas corruptas de victimización, sino los dogmas conservadores de aplicación irrestricta de la ley sin importar los usos y costumbres de los grupos 
dominados, o bien, la práctica de valores liberales como ejemplos a seguir de una cultura dominante.

Se trata de disposiciones que favorecen un sistema de leyes que legitiman las diferencias entre los grupos e individuos, así como la indiferencia de grupos favorecidos del sistema con respecto a quienes son estigmatizados o culpabilizados de crímenes asociados a sus estereotipos sociales (Chavarría, 2013).

Es así como las teorías de representaciones, habitus, campos y capitales explican los enfoques de victimización y sus correspondientes ciclos e intervenciones.

Desde la teoría de las representaciones sociales, las víctimas son instrumentos de emancipación histórica, ya sea por su desviación social, su apelación a las leyes escritas o su encarnación del abuso de poder del Estado para con los sectores vulnerables, marginados o excluidos de la sociedad civil (Zúñiga, 2011).

Desde la teoría del habitus, campos y capitales, las víctimas son calibradas por sus juegos de poder y posiciones discursivas que, no sólo advierten un sistema de reproducción de la dominación social, sino una esfera civil con los recursos indispensables para emanciparse simbólicamente de la violencia ejercida por la propaganda del Estado o por sus estrategias punitivas (Carreón et al., 2013).

De este modo, la información concerniente a la fase de objetivación, anclaje y naturalización advierte una tendencia incremental en los casos de homicidios dolosos en México. Durante el periodo que va de 2005 a 2010, en Chihuahua se incrementaron los casos hasta un $700 \%$ mientras que en Guerrero se incrementó en un $150 \%$ un poco más de la media nacional de $127 \%$. Es decir, en la región de Ayotzinapa, el Estado de Guerrero ocupó el lugar 13 de 32 posibles, mientras que la prensa lo asoció con los casos de delincuencia organizada como la entidad más violenta y a su capital Chilpancingo como la tercera más violenta en el año 2013 con respecto a los demás municipios (véanse gráficos 2 y 3 ).

Es así como la violencia, indicada por el número de homicidios y la difusión de tres medios impresos de circulación nacional convergen en identificar al Estado de Guerrero como la entidad más insegura al relacionarla con la delincuencia organizada.

Desde un enfoque conservador, la benevolencia por naturaleza de la mayoría no sólo estaría comprometida por la violencia natural de una minoría, sino además estaría condicionada por la misma delincuencia organizada que, aunque es una minoría, supone un poder destructivo de las instituciones y sus leyes escritas garantes de la justicia (Torres, 2013).

Desde una visión liberal, el caso de Guerrero (Ayotzinapa) es una oportunidad para la observación de las diferencias y la aplicación a pie juntillas de las leyes escritas. Se 
trata de un enfoque en el que los derechos humanos al ser trastocados generan una serie de leyes para resarcir las diferencias y orientarlas a la paz pública.

Por último, desde el progresismo, el incremento de la violencia y la inseguridad suponen la reducción a su mínima expresión de las instituciones que ya actuaban sesgadamente a favor de quienes tienen los recursos para cometer delitos y quedar impunes de toda responsabilidad.

Se advierte una tendencia de la difusión sistemática desde 2013 de aquellas entidades circunvecinas a Ayotzinapa, pero la especificidad de los encuadres indicaría el tipo de acción que se gestó en un periodo de tiempo determinado en la entidad de estudio con respecto a la atención a víctimas.

\subsection{Formulación:}

¿Cuáles son las representaciones sociales que los medios impresos difundieron sistemáticamente en torno a la atención a víctimas por el caso de ayotzinapa como respuesta a la propaganda informativa del Estado?

\subsection{Hipótesis nula:}

Las representaciones sociales en torno a la propaganda del Estado con respecto a las víctimas de Ayotzinapa fueron objetivadas, ancladas y naturalizadas como respuestas de grupos disidentes más que como una política pública o programa institucional.

\section{METODOLOGÍA}

\subsection{Diseño.}

Se llevó a cabo un estudio exploratorio y retrospectivo.

\subsection{Muestra.}

Se realizó una selección no probabilística de 261 notas de prensa considerando la circulación nacional y el contenido alusivo a las víctimas de la desaparición de 43 normalistas de Ayotzinapa, Iguala-Guerrero (Costa del pacífico de México).

\subsection{Instrumento.}

Matrices de análisis de contenido que incluyen datos básicos de registro e inferencia del encuadre relativo a la relación que guardan las notas con la acción de grupos, instituciones y entidades políticas.

\subsection{Procedimiento.}


Se vacío la información en la matrices y se calificó cada nota a partir de los criterios de encuadre que para el caso se asignó un valor de cero a aquellas notas que no aludieron a la acción de grupos organizados de la sociedad civil, instituciones o entidades políticas en torno a la atención a víctimas (familiares y amistades) de los 43 desaparecidos de Ayotzinapa.

\section{RESULTADOS}

Los resultados muestran un sesgo sistemático progresista de La Jornada con respecto a El Reforma y El Universal en cuanto al encuadre de atención a víctimas por parte de grupos organizados de la sociedad civil, instituciones o gobierno

Es decir, desde un enfoque progresista, La Jornada alude al poder que determina las diferencias entre gobernantes y gobernados con respecto a la impartición de justicia, preferentemente en cuanto a la atención a víctimas.

La Jornada enfoca su difusión informativa a la participación de la sociedad civil como actor clave en la atención a víctimas, en seguida a las instituciones y al final a los gobernantes como administradores de la seguridad pública e impartición de justicia.

Es el caso mismo de El reforma con excepción del encuadre político en el que El Universal resulta tener un mayor sesgo de difusión, pero que en los casos de la acción civil e institucional advierte una tendencia inferior a la de El Reforma.

En síntesis los hallazgos advierten la emergencia de un encuadre favorable a la organización de la sociedad en comparación a la acción gubernamental en materia de atención a víctimas para el caso de los 43 desaparecidos de Ayotzinapa.

\section{DISCUSIÓN}

El aporte del presente trabajo al estado del conocimiento radica en el establecimiento de una tendencia favorable a la acción de grupos de la sociedad civil en cuanto a la atención a víctimas por las desapariciones de los 43 normalistas de Ayotzinapa.

Sin embargo, la literatura revisada advierte sobre el encuadre de verificabilidad y verosimilitud que pretende no sólo establecer como tema central en la agenda a la atención a víctimas, sino además inducir la evaluación de la acción gubernamental.

En este sentido, los estudios de Carreón et al., (2013) señalan que el encuadre de verificabilidad es una representación de la rectoría del Estado en materia de seguridad pública. Se trata de un ciclo de emociones y desconfianza hacia las autoridades al considerar que su gestión orienta la ingobernabilidad. En contraste, el encuadre verosimilitud puntualiza la rectoría del Estado como administrador de la seguridad y procurador de justicia, pero sin la obligación de atender a las víctimas, 
ya que las considera como efectos colaterales en el combate a la delincuencia o la procuración del delito, razón por la que sus recursos más bien se dirigen a reducir los riesgos y la incertidumbre de la delincuencia organizada que los medios resaltan como evidencia de ingobernabilidad.

En el presente trabajo se advierte la lógica de verificabilidad y verosimilitud en el momento en que la prensa resalta la participación de grupos organizados de la sociedad civil y soslaya la administración gubernamental.

Sin embargo, la aproximación progresista, a diferencia del encuadre liberal de verosimilitud y verificabilidad de los medios impresos, supone una difusión sistemática de la acción civil en relación con la opacidad del gobierno y sus instituciones porque reconoce el sesgo de las leyes escritas al favorecer a quienes poseen los recursos para afrontar la delincuencia y culpabilizar a quienes no cuentan con tales recursos.

En este sentido es menester profundizar en el estudio de la aproximación conservadora, liberal y progresista con la finalidad de esclarecer los efectos de los encuadres periodísticos sobre sus lectores.

\section{CONCLUSIONES}

La atención a víctimas, familiares y amistades de los 43 desaparecidos de Ayotzinapa supone el estudio de los medios impresos como difusores de valores conservadores, liberales o progresistas que, en la prensa de circulación nacional están asociados a la acción de grupos organizados de la sociedad civil más que a las políticas de prevención del delito, impartición de justicia o combate a la delincuencia.

Tal hallazgo permitirá explicar la construcción de una agenda pública en materia de seguridad, violencia y atención a víctimas que está centrada en la acción de la sociedad civil más que en la rectoría del estado.

La agenda de seguridad al estar constituida por representaciones y habitus supone la atención a víctimas desde una perspectiva diferente a la conservadora, liberal o progresista, ya que la historia de tal fenómeno advierte un surgimiento de un escenario de gobernanza más que de gobernabilidad o ingobernabilidad. Es decir, los medios anticipan la emergencia de una estructura de discusión, acuerdos y corresponsabilidades impulsada por la sociedad civil más que por las iniciativas de los gobernantes.

\section{REFERENCIAS}

Añanos, F. (2012). "Violencias y exclusiones en el medio penitenciario. Enfoque socio-educativo y de la paz." Convergencia, 59, 13-41 
Carreón, J., Hernández, J., Morales, M. y García, C. (2013). "Hacia la construcción de una esfera civil de identidad y seguridad pública." Eleuthera, 9 (2), 99-115

Chavarría, C. (2013). "Estructura social y locus de control en colegios catalogados como violentos de zonas urbanas y rurales. Evidencias de su relación como insumo para la promoción de una cultura de la paz." Reflexiones, 92 (1), 77-96

Clemente, R., Villanueva, L. y Cuervo, K. (2013). "Evolución y reconocimiento de los transgresores morales y socio-convencionales en menores." Convergencia, 61, 15-34

Concimance, A. (2013). "Memoria y violencia política en Colombia. Los marcos sociales y políticos de los procesos de reconstrucción de memoria histórica del país." Eleuthera, 9 (2), 13-38

Dorantes, G. (2012). "Agenda comunicativa para la implementación exitosa de políticas públicas." Convergencia, 59, 117-139

Fondevilla, G. y Quintana, M. (2013). "Juego de palabras: los discursos presidenciales sobre el crimen." Estudios Sociológicos, 31 (93), 721-754

García, C., Carreón, J., Hernández, J. y Méndez, A. (2013). "Sistemas de violencia sociopolítica." Polis, 12 (36), 343-365

Gasca, E. y Olvera, J. (2011). "Construir ciudadanía desde las universidades, responsabilidad social universitaria y desafíos ante el siglo XXI." Convergencia, $56,37-58$

Jiménez, F. (2009). "Hacia un paradigma pacífico: la paz neutra." Convergencia, Número Especial, 141-190

Jiménez, F. (2012). "Conocer para comprender la violencia: orígenes, causas y realidad." Convergencia, 58, 13-52

Taguenca, J. (2012). "La opinión política de los jóvenes universitarios de Hidalgo, México. Un análisis desde la teoría del campo." Convergencia, 60, 45-77

Tena, J. (2010). "Hacia una definición de la virtud cívica." Convergencia, 53, 311-337

Torres, L. (2013). "Organizaciones juveniles: por el camino de las identidades políticas." Eleuthera, 9 (2), 156-185

Uvalle, R. (2011). "Las ciencias sociales y las políticas públicas en el fortalecimiento del arte de gobernar." Convergencia, 55, 37-68

Zúñiga, A. (2011). "Teoría de la Justicia Distributiva: una fundamentación moral del derecho a la protección de la salud." Convergencia, 55, 191-211 